\title{
Personal health budgets: A new way of accessing complementary therapies?
}

\author{
Jim Rogers* \\ University of Lincoln, Hull school of health and social care, Derek Crothall Building, George St, Hull HU1 3BW, United Kingdom
}

Keywords:

Personal health budgets

Complementary and alternative therapies

Chronic illness

Evidence based medicine

\begin{abstract}
A B S T R A C T
The popularity and use of complementary and alternative therapies and medicines (CAM) has remained high in the UK and many other countries over at least the last two decades. Access to such modalities via publicly funded health and welfare systems has remained very limited over the same period. Personal health budgets, designed to offer significant control and personal choice over health care, offer a potential mechanism for some individuals to access publicly funded CAM treatments more directly. This development brings into sharp focus debates about evidence based health care and conflicts between public policy which is geared towards consumer choice and public policy which is based on certain forms of scientific evidence. This paper will examine some of the arguments for allowing access to CAM via personal health budgets, and potential objections and obstacles to this.
\end{abstract}

(c) 2010 Elsevier Ltd. All rights reserved.

\section{Introduction}

Many commentators have observed that an increasingly significant force in the welfare systems of most modern developed societies is that of consumerism. ${ }^{1}$ Broadly this term refers to a view of public services as commodities, and increasing attention being paid to protecting and satisfying the individual needs and wishes of those who use, or 'consume' such services. Governments have responded to this demand by adapting, to varying degrees, many state run public services, in attempts to offer greater responsiveness and greater choice.

UK governments since 1979 have enacted a series of reforms to public services in this direction. For example, The Thatcher government in the UK (1979-1990) introduced market forces into health and social care via the formation of the internal market in the NHS and a similar separation of purchasers and providers in social care with the introduction of the Griffiths reforms and the 1990 NHS and Community Care Act. ${ }^{2}$ The New Labour government (1997-2010) continued the direction of travel with further reforms to public services aimed at increasing diversity, influence and choice for users of public services. ${ }^{3}$ The coalition government elected in 2010 was quick to produce plans for change in the NHS, in the white paper 'Equity and Excellence'. This document makes it very clear that the theme of patient choice will be even more central to health policy "The NHS also scores relatively poorly on being responsive to the patients it serves. It lacks a genuinely patientcentred approach in which services are designed around individual

\footnotetext{
* Tel.: +44 1482311408

E-mail address: jrogers@lincoln.ac.uk.
}

needs, lifestyles and aspirations", " We will put patients at the heart of the NHS, through an information revolution and greater choice and control", "Shared decision-making will become the norm: no decision about me without me". 4

\section{Direct payments, personal budgets and health care}

One method of giving users significant choice and control is via the mechanism of a personal budget. This enables a person to be offered, in lieu of directly provided services, an equivalent sum of money, for them to purchase their own care and services. In the field of social care campaigning by various groups led to the setting up a set of 13 pilot projects for personal budgets in social care across local authorities in England from the end of 2005. Unusually, evaluation of these projects using an RCT was part of the pilot project process. Illustrating the dictum that it is often the case that policy drives evidence rather than the reverse, the care services minister at the time, announced that personal budgets were the future of social care, well before the evaluation was complete. Nevertheless the evaluation report did indicate that personal budgets provided increased choice and control and positive outcomes in terms of health and well being for most service user groups. ${ }^{5}$ The policy has been rolled out nationally and local authorities now have challenging targets in relation to the number of service users who are using this mechanism of support. At the end of 2009, over 25,000 social care service users in England and Wales were receiving personal budgets and the aim is that $30 \%$ of those who receive community based services will receive a personal budget by April $2011 .^{6}$

One of the issues which arose from the social care pilot projects, was that of the dividing line between health and social care. 
Because the two are funded differently this becomes an important issue for both service users and those setting up and providing services. To meet a persons assessed needs, a range of services and interventions may be offered, and there is often no obvious point at which a health need becomes a social care need.

In fact researchers found that many people receiving direct payments for social care used them to purchase a range of services traditionally defined as health care.

These included physiotherapy, foot dressings and so on but also CAM therapies for pain relief and relaxation. ${ }^{5}$

Moreover, the evaluation of the programme found that more than half of personal budget holders reported better health and $57 \%$ of family care givers reported better health, ${ }^{7}$ even though the budgets were specifically set up to fund social care only and at the time the department of health were adamant that personal budgets would never be introduced for health care because they flouted the fundamental principles of the NHS.

Around this time Glasby et al. noted that what was remarkable about direct payments/personal budgets was "the extent to which they mirror key policy goals in the UK NHS yet have historically been resisted in health care". ${ }^{8}$ Also at this time developments in relation to health care such as the Darzi review were calling for increased choice and the use of personalisation within the NHS to achieve this kind of choice. One of the key stated aims of the reforms recommended by this review was to empower patients. "The NHS needs to give patients more rights and control over their own health and care, for more personal care". ${ }^{9}$ A number of documents from think tanks such as the Demos Foundation ${ }^{10}$ and The Social Market Foundation ${ }^{11}$ together with reports from Canada, the USA, the Netherlands and Australia which all had experience of personal budgets in health care, ${ }^{8}$ supported their use as a very effective mechanism for giving patients choice, control and better outcomes in relation to health care.

The result of these various drivers was the setting up in the UK, in 2009, of 75 pilot projects of personal health budgets (PHBs). It is notable that half of all primary care trusts (PCTs) in the country applied to become pilot sites. The aim was initially to offer these budgets to people in four particular groups: those receiving NHS continuing health care; those with long term conditions; those with mental health problems; and those receiving end of life care. ${ }^{12}$ These pilot projects are running for a period of three years and a subset of 20 are being evaluated by the Personal Social Services Research Unit at the University of Kent. The health white paper produced by the coalition government describes a continuing commitment to this programme.

When the pilots commenced there was not a legal mechanism for offering direct cash payments to individual health service users. Whilst social care users have legally been able to receive direct finance in the shape of direct payments since the 1996 direct payments act, the personal health budget pilots were set up with notional budgets, or in some cases budgets held in some kind of trust set up on behalf of the patient by a third party. ${ }^{12}$ The Health Act 2009, which received Royal Assent in November 2009, changed the law in this regard and direct payments were available to PHB holders from Summer 2010.

\section{Complementary medicine, chronic illness and personal budgets}

This is clearly an interesting development from the point of view of complementary medicine for several reasons. Firstly, the fact that the kind of NHS users who are being offered PHBs are typically the kind of people who use complementary therapies, i.e. those with chronic, long term conditions who tend to consume a lot of NHS resources and who do not experience significant benefit from these NHS interventions. ${ }^{13,14}$
Secondly the fact that there is good evidence that many of those who would most like to access complementary therapies are prevented from doing so for reasons of cost and access ${ }^{15-17}$ and that PHBs may provide a new mechanism of access for many people. Thirdly, that this development brings into sharp focus the possible conflict between drives on the one hand to increase the amount of choice and control that service users can have, and on the other the drive for publicly funded interventions to be evidence based according to very specific types of evidence.

In relation to CAM use and chronic illness, a number of surveys have been undertaken in the UK and elsewhere of those who use complementary medicine, which have given some insight into the numbers and some of the characteristics of such users. A systematic review of studies found that the most reliable estimates suggested consistent consultation rates with CAM practitioners of $20 \%$ or more of the population in a variety of countries including South Australia, the US and the UK. ${ }^{18}$ People with chronic illness use CAM modalities 2-5 times more than others. ${ }^{19}$ One Dutch study found that $33 \%$ of the chronically ill population use CAM. ${ }^{20}$ Looking at it from a different perspective a study examining the health status of people using CAM practitioner services in four English counties found that $60 \%$ of CAM users reported having a chronic illness or disability, significantly higher that the general population. ${ }^{21}$ It is estimated that $80 \%$ (or up to 180 million) GP visits in the UK are related to chronic illness. ${ }^{22}$ With an ageing population this will only increase in the coming years. ${ }^{23}$ A recent review of a large number of studies confirmed a strong association between chronic illness, particularly with multiple conditions; and CAM use. ${ }^{24}$

Many professionals within the NHS recognise the limitations of existing evidence based interventions for many chronic conditions and we know that some will prescribe CAM therapies for where such an 'effectiveness gap' has been described. ${ }^{25}$ Indeed it was estimated that $39.5 \%$ of GP practices provided access to some form of CAM in $1995^{15}$ and that this had risen to $50 \%$ by $2001 .{ }^{26}$ One detailed study of those with long term conditions who use CAM concluded that such use should be understood as a critical component of self care management in general and should be viewed not as a search for a miracle cure or a rejection of conventional medicine but as an attempt to take personal responsibility for health and a pragmatic attempt at managing a chronic condition as well as possible. ${ }^{4}$ From this perspective CAM use should be welcomed and encouraged as a good example of the kind of self management and assumption of responsibility for health which Department of Health Policy is advocating. ${ }^{27}$ Indeed the kind of active role which is adopted by those who seek out and inform themselves about CAM therapies for their chronic ailments is exactly the kind of approach which the Department of Health expert patient programme recommends. ${ }^{28}$

In terms of the evidence relating to access and demographic factors, surveys consistently suggest that those who use CAM are better educated. The latest review of research suggests that this factor is consistently associated with CAM use. The relationship between income and CAM use is less consistent though a large number of studies show an association between higher income and CAM use than not. ${ }^{24}$

It has been noted that CAM use is higher among those with chronic illness and that many such users express great satisfaction with such interventions. It is likely to be the case that those with chronic illness are much more likely to live on state benefits or be on lower incomes. Indeed there is a lot of evidence that chronic illness is socially patterned and that there is a gradient with those on lowest incomes experiencing the highest levels of ill health. ${ }^{29,30}$ Whilst many GP practices provide some form of access or referral to CAM, as noted earlier, it is also the case that increasingly, such access is less likely to be funded by the NHS. ${ }^{26}$ Following campaigns by small groups of professionals some routes of access have been 
cut back in recent years. Referrals to the NHS homeopathic hospitals for example, have been reduced by many PCTs. ${ }^{31}$ Those on lower incomes are currently far less likely to be able to use CAM since the economics and the time consuming nature of most CAM interventions make them relatively expensive at the point of delivery, without any public subsidy.

Critics of personal health budgets have suggested that they may lead to greater health inequalities as the more articulate and well educated know how to work the system. ${ }^{32}$ Evidence suggests however that without public subsidy and public access mechanisms, individuals with chronic health problems, who would like to utilise CAM, are less likely to have the means or the knowledge to access them. In this sense PHBs may actually lead to far greater equity when it comes to access to CAM treatments.

\section{The evidence debate}

The drive towards evidence based health care has been very strong and growing since the $1980 \mathrm{~s}^{33}$ In using this term, many commentators implicitly or explicitly refer to specific types of evidence, and typically refer to the scientific hierarchy in which RCTs and systematic reviews and meta-analysis enjoy pride of place.

Many complementary therapies are not supported by a strong evidence base in these terms. ${ }^{34}$ However, the same therapies often enjoy significant popular usage and many service users believe strongly that such therapies are beneficial. If public policy is to driven by issues of choice and user control, should evidence be a secondary consideration? Many scientists and professionals think that sufficient levels of certain types of scientific evidence should be the primary consideration in directing public resources to health care interventions. ${ }^{35}$ Others suggest that the primary questions should be different ones and that the most appropriate evidence relates to whether an intervention is safe, meets a person's identified need and whether they are satisfied with the outcome in the real world, rather than whether that intervention has been shown to be statistically different in the restricted population and environment of a randomised trial. ${ }^{36}$

Unsurprisingly service users and health professionals who support CAM are broadly in favour of the development of PHBs: other health professionals who are committed to the EBM agenda have portrayed it as misguided. The NHS Alliance have come out in favour and noted that " patients will be allowed to go outside of NHS guidelines". However, a negotiator for GPs stated that "I think there seems to be some confusion in Government policy. On the one hand they have been quite clear that the NHS should use resources based on evidence-based guidance developed by NICE, but there seems to be some confusion about the degree of flexibility patients will have. For example most complementary therapies are not supported by NICE guidance". 37

Such comments go to the heart of debates about the meaning of evidence based medicine. The established hierarchy of evidence places a big emphasis on the very specific and well delineated interventions, which have been able to demonstrate efficacy within the tightly controlled conditions of a clinical trial.

But there is also good evidence that factors other than the specific efficacy of a tightly defined intervention can have significant benefits to health. There is a strong body of evidence, for example, that demonstrates that giving patients choice and control leads to better health outcomes and even greater longevity. In one study people living in care homes who were simply given a plant to look after lived significantly longer. ${ }^{38}$ A study of women undergoing surgery for breast cancer noted that those women given a choice of treatment, with the agreement of the surgeon, had less post operative depression than those whose surgeon insisted on either mastectomy or lumpectomy. ${ }^{39}$ In a large RCT, the effect of giving a choice of formats for a programme of heart disease management improved physical and psychosocial functioning. ${ }^{40}$

In this sense, a commitment to evidence based interventions could lead to a view that the choice and control provided by PHB's mean that they are strongly evidence based and a completely rational direction for health policy, rather than misguided. Regardless of the specific interventions chosen by an individual, and as long as they are not harmful, the fact of having the power to choose, may be significantly beneficial for a patient with a long term problem which has not responded to conventional health interventions.

This becomes an issue of which type of knowledge becomes privileged. Will it be knowledge from the accepted hierarchy of evidence? Will it be consumer led? Or will it be based on professional power and judgement?

\section{Personal health budgets in practice}

So far an argument has been made for providing access to CAM therapies via the emerging mechanism of personal health budgets. Is this likely to happen to any significant extent in practice? What barriers or objections might be raised to such a move?

Experience in social care demonstrated significant professional resistance to the introduction of both direct payments and personal budgets. ${ }^{8}$ Researchers also found that, once the concept was operationalised, the benefits to service users become apparent, and professionals become excited about new ways of working in partnership rather than worried about losing their job or their role, the resistance from professionals was significantly reduced. ${ }^{41}$

There is no single model which describes exactly how personal budgets will work in practice or how people might access complementary therapies using such budgets. The essential principle relates to putting the patient in control and ensuring that they have the choice and resources to access services which meet their assessed needs. There are certain activities and services which are proscribed, such as the purchase of alcohol or tobacco, gambling, repayment of personal debt, and the payment of college or educational fees. Other than that the Department of Health guidance states only that the patient must use their budget to 'procure services specified in their care plan'. ${ }^{12}$

Some authors think that GPs should gate keep and recommend the treatment provider to be used, after diagnosis has been made. ${ }^{8}$ The patient would then spend their allocated budget with that provider. Another model suggests that patients should be able to choose from a menu of approved treatment providers without direct recommendations from a GP or other professional and the more radical model suggests a wider set of choices be made available to patients. ${ }^{8}$

Glasby et al. have suggested that, for those with long term conditions, a full assessment of predictable long term care needs would be followed by the costing of resource implications for a period of perhaps one year, to determine a budget. The patient would then be given a cash sum in the same way as social care direct payments. The patient may seek assistance from health professional or user support organisations to manage the process, but they would be free to choose their own care so long as it broadly met their identified needs. ${ }^{8}$

With regard to CAM provision it was noted above that there were examples from the social care evaluation programme of people using their social care personal budget to fund CAM treatments. There are already a number of examples from the personal health budget pilots of similar decisions being made, and of them making a real difference in peoples lives. To take just one example, research in Norfolk in 2009 found that those with long term conditions who used complementary treatments regularly "often 
described them as being more effective and valuable to the management of their condition than the prescription drugs they use". 42

\section{Risk issues}

A number of objections have been raised to the shifting of both resources and responsibility from professionals employed by the state to individual users of welfare services. One such objection in relation to both health and social care relates to quality and standards. Professionals employed by local authorities and the NHS are trained to certain standards and are subject to significant regulation and monitoring.

In social care there has been significant debate in relation to the employment by service users of untrained personal assistants, the terms and conditions of employment of such assistants and the right of users to choose not to insist on regulatory checks such as CRB clearance, and minimum levels of training. ${ }^{43}$ In health there are concerns in relation to individuals choosing to purchase services from untrained and potentially dangerous practitioners of non conventional therapies. Critics of CAM often point to a number of related risks. The most commonly articulated is that people may use CAM as a complete alternative and visit practitioners who fail to diagnose serious health problems, with resulting morbidity or mortality. ${ }^{44}$ These critics acknowledge that there is little systematic research into this area and therefore any such evidence is anecdotal.

With personal health budgets it will always be the case that there is some gate keeping or oversight by GPs or other health professionals, and negotiation with those professionals regarding the actual use of the budget. In addition the department of health guidance for pilot projects is pointing people towards practitioners who are registered with the recently established Complementary and Natural Health care Council (CNHC), as a means of ensuring safety and minimum standards. ${ }^{45}$ Giving choice and responsibility to individuals and letting go of a little professional power and control inevitably entails some amount of risk. What should be considered is whether the significant gains which may result more than outweigh the small amount of risk.

\section{Conclusion}

In recent years the increasing popularity of CAM interventions has been countered with a backlash from a movement which characterises CAM as lacking in credible evidence and which argues as a consequence that public monies should not be given to any interventions of this kind. This paper has argued for a different perspective on evidence. With very clear evidence that choice and control are beneficial to health, the moves towards greater choice in health care and more personalised care should be welcomed. The mechanism of personal budgets is demonstrably good for health, and whether an individual chooses to use their budget to purchase CAM treatments or not should be a matter for negotiation with their health care professionals but ultimately a matter of personal choice. It is certainly clear that the types of individuals who are receiving personal health budgets receive limited benefits from traditional NHS care, and clear that such care is expensive. Such individuals would often choose CAM treatments but have often been denied access to them. The provision of CAM via personal health budgets to those with long term conditions, chronic illness, mental illness, and those receiving end of life care, can potentially offer many gains, and there is little to lose by allowing such access. If the loud rhetoric of patient choice is to mean anything then this is certainly a direction in which the NHS should continue to move.

\section{Conflict of interest statement}

The author declares that he has no conflict of interest.

\section{References}

1. Baldock J. On being a welfare consumer in a consumer society. Social Policy and Society 2003;2(1):65-71.

2. McDonald A. Understanding community care. Palgrave; 2006.

3. Scourfield P. Social care and the modern citizen: client, consumer, service user, manager and entrepeneur. British Journal of Social Work 2007;37:107-22.

4. Department of Health. Equity and excellence. The Stationary Office; 2010.

5. Glendinning C, Challis D, Fernandez J, Jacobs S, Jones K, Knapp M, et al. Evaluation of the Individual Budgets Pilot Programme: Final Report. Personal Social Services Research Unit, University of Kent, Canterbury; 2008.

6. Community Care, Personalisation Milestones, Community Care 15/9/09.

7. Brewis R, Fitzgerald J. Citizenship in health self direction theory to practice. In: Control; 2010.

8. Glasby J, Le Grand J, Duffy S. A healthy choice? Direct payments and healthcare in the English NHS. Policy and Politics 2009;37(4):481-97.

9. Darzi. High quality care for all - NHS next stage review final report. The Stationary Office; 2008.

10. Leadbeater C, Bartlett J, Gallagher N. Making It Personal. Demos; 2008.

11. Alakeson V. Putting patients in control: the case for extending self-direction into the NHS. Social Market Foundation; 2007.

12. Department of Health. Understanding personal health budgets. The Stationary Office; 2009

13. Eisenberg D, Kessler R, Foster C, Norlock F, Calkins D, Delbanco T. Unconventional medicine in the United States: prevalence, costs and patterns of use. The New England Journal of Medicine 1993;328(4):246a-52a.

14. Thorne $\mathrm{S}$, et al. Complementary/alternative medicine in chronic illness as informed self-care decision making. International Journal of Nursing Studies 2002;39(7):671-83.

15. Thomas K, Nicholl J, Fall M. Access to complementary medicine via general practice. British Journal of General Practice 2001;51(462):25-30.

16. Andrews G. Private complementary medicine and older people: service use and user empowerment. Ageing $\mathcal{E}$ Society 2002;22:343-68.

17. Cartwright T. "Getting on with life": the experiences of older people using complementary health care. Social Science and Medicine 2007;64:1692-703.

18. Harris P, Rees R. The prevalence of complementary and alternative medicine use among the general population: a systematic review of the literature Complementary Therapies in Medicine 2000;8:88-96.

19. Van den Brink-Muinen A, Rijken P. Does trust in health care influence the use of complementary and alternative medicine by chronically ill people? BMC Public Health 2006;6:188.

20. Wijk M, Eenink G, Waart F, Loon A, Schouten E. Gebruik van alternatieve geneeswijzen en chronische aandoeningen: de associatie nader bekeken. [Use of alternative treatments and chronic illnesses; a close view on the association]. TSG 1995;73:83-9.

21. Ong C, Peterson S, Bodeker G, Stewart-Brown S. Health status of people using complementary and alternative medical practitioner services in 4 English counties. American Journal of Public Health 2002;92(10):1653-6.

22. Department of Health. Improving chronic disease management. The Stationary Office; 2004.

23. Age concern facts, figures and research. Age Concern; 2007.

24. Bishop F, Lewith G. Who uses CAM? A narrative review of demographic characteristics and health factors associated with CAM use. Evidence-Based Complementary and Alternative Medicine 2010;7:11-28.

25. Fisher P, Van Haselen R. Effectiveness gaps in general practice: the potential of complementary medicine. Focus on Alternative and Complementary Therapies $2003 ; 8$.

26. Thomas KJ, Coleman P, Nicholl JP. Trends in access to complementary or alternative medicines via primary care in England: 1995-2001 results from a follow-up national survey. Family Practice 2003;20(5):575-7.

27. Department of Health. Supporting people with long term conditions to self care: a guide to developing local strategies and good practice. The Stationary Office; 2006.

28. Department of Health. The expert patient: a new approach to chronic disease management for the 21st century. The Stationary Office; 2001

29. Jones K, Duncan C. Individuals and their ecologies: analysing the geography of chronic illness within a multilevel modelling framework. Health \& Place 1995;1 (1):27-40,

30. Graham H. Socio-economic inequalities health in the UK. Evidence on patterns and determinants. Disability rights commission; 2004.

31. Praities N. Homeopathy victim of PCT funding cuts. Pulse; 31st Jan 2008.

32. Norris R. All you need to know about personal health budgets. Pulse; 01 August 2008.

33. Dopson S, Locock L, Gabbay J, Wan F, Fitzgerald L. Evidence based medicine and the implementation gap. Health 2003;7(3):311-30.

34. Lewith G. Research in complementary and alternative medicine: some considerations, www.evidence.nhs.uk [accessed 12.01.10].

35. Sackett DL, Rosenberg WM, Gray JA, Haynes RB, Richardson WS. Evidence based medicine: what it is and what it isn't. BMJ 1996;312(7023):71-2. 
36. Robson C. Real world research: a resource for social scientists and practitionerresearchers. 2nd ed. Wiley; 2002.

37. Praites N. Personal budgets to allow patients to buy homeopathy and acupuncture. Pulse; 30th October 2009

38. Rodin J, Langer J. Long-term effects of a control-relevant intervention with the institutionalized aged. Journal of Personality and Social Psychology 1997;35 (12):897-902

39. Fallowfield L, Maguire P, Baum M, Hall A, Ahern R. Psychological effects of being offered choice of surgery for breast cancer. BMJ 1994;309:448.

40. Clark N, Janz N, Dodge J, Mosca L, Lin X, Long Q, et al. The effect of patient choice of intervention on health outcomes. Contemporary Clinical Trials 2008;29(5):679-86.
41. Glasby J, Littlechild R. Direct payments and personal budgets: putting personalisation into practice. 2nd ed. Policy Press; 2009.

42. IPSOS Mori research on personal health budgets for NHS; 2009.

43. Boxall K, Dowson S, Beresford P. Selling individual budgets, choice and control; local and global influences on UK social care policy for people with learning difficulties. Policy and Politics 2009;37(4):499-515.

44. Ernst E. 'First, do no harm' with complementary and alternative medicine'. Trends in Pharmacological Sciences 2007;28(2):48-50.

45. CNHC. Personal health budgets - opportunity for CNHC registrants. http:// www.cnhc.org.uk/pages/newsManager.cfm?page_id=2\&news_id=66; 2010 [accessed 17.10.10] 